\title{
Deformation behaviour of beta phase with similar chemical composition in beta and alpha+beta titanium alloys
}

\author{
Xin Xu*, Ioannis Bantounas, David Dye
}

Dept. of Materials, Royal School of Mines, Imperial College London, London SW7 2AZ, UK

*Corresponding author: xin.xu@imperial.ac.uk, xxu2010@hotmail.com

\begin{abstract}
:
Twinning-induced plasticity (TWIP) and transformation-induced plasticity (TRIP) in $\beta$ titanium alloys have been attracting significant interest, since they offer the possibility to provide work hardening and thus, ductility. Here a quaternary Ti-Al-Cr-Mo metastable $\beta$ alloy has been designed with an excellent combination of strength ductility that exploits the TWIP and TRIP effects. Its engineering yield strength, tensile strength and total elongation are $737 \mathrm{MPa}, 999 \mathrm{MPa}$ and $24 \%$, respectively. In order to increase the yield strength but retain ductility, an attempt has been carried to design an $\alpha+\beta$ alloy with a bimodal microstructure. The composition of the $\beta$ phase in the $\alpha+\beta$ alloy was tuned to provide deformation twinning of the $\beta$ phase. The content of the major $\alpha$ and $\beta$ stabilising elements, i.e. Al, $\mathrm{Cr}$ and $\mathrm{Mo}$, in the $\beta$ phase of the $\alpha+\beta$ alloy was similar to the $\beta$ alloy, but the deformation twinning was not observed in the $\beta$ phase. It is suggested that this may be due to over-stabilisation of the $\beta$ phase and/or to the different stress/strain and dislocation distributions in the $\alpha+\beta$ alloy caused by the presence of $\beta$ phase.
\end{abstract}

\section{Introduction}

Titanium (Ti) alloys have been widely used in different industries due to their high strength-to-density ratio, good hardenability and excellent corrosion resistance [1]. Despite these advantages, titanium components in service suffer a lack of strain hardening which results in both notch sensitivity and in relatively low ductility compared to, e.g., steels. Therefore, there is still a strong desire for high strength, high ductility Ti alloys, particularly in aerospace and automotive industries which require high specific mechanical performance. Conventional strengthening mechanisms such as grain refinement and precipitation hardening have not been successful in overcoming these concerns. However, transformation-induced plasticity (TRIP, due to the $\alpha^{\prime \prime}$ phase) and twinning induced plasticity (TWIP) have recently been observed in metastable $\beta$ Ti alloys, providing high ductility and significant strain hardening [2], similar to that observed in high- or medium-manganese steels [3]. As a result, the TRIP and TWIP effects have been attracting great attention from both the academic and industrial communities. The deformation mechanism in $\beta$ Ti alloys is suggested to be determined by the stability of the $\beta$ phase [4]. As the stability of the $\beta$ phase decreases, the main deformation mechanism changes from dislocation slip to twinning (TWIP) and then to stress-induced martensite (TRIP) [5]. Usually, the dislocation slip mechanism leads to a relatively high yield strength but low elongation and strain hardening. TWIP and TRIP mechanisms can improve the uniform elongation and strain hardening dramatically but the yield strength is relatively low [6,7]. Moreover, the yield strength of TRIP $\beta$ Ti alloys is usually lower than that of the TWIP counterparts, but the uniform elongation of TRIP $\beta$ Ti alloys is larger [6,7]. Hence, efforts have been made to tailor the stability of the $\beta$ phase and thus control the deformation mechanisms to improve the mechanical properties of the alloys. The d-electron alloy design approach is often used to design $\beta$ Ti alloys which possess TWIP and/or TRIP $[2,4,5,8,9]$. This method associates the $\beta$ phase stability with the bond order ( $\mathrm{B}_{0}$ ) which is the average covalent band strength between Ti and alloying elements and Md which is the average d-orbital energy level in a body-centred cubic cluster. The chemical composition of the $\beta$ phase determines its stability according the d-electron alloy design approach. Based on this method, several $\beta$ Ti alloys have been designed, e.g., Ti-12Mo [2], Ti-9Mo-6W [10], Ti-8.5Cr-1.5Sn [11], Ti-3Al-5Mo-7V-3Cr [5] (all compositions in wt. \%). Most of these alloys exhibit the twinning deformation mechanism which enhances both the strain hardening and ductility via the dynamic Hall-Petch effect [2]. However, the yield strength of these alloys needs further improvement. Ti alloys with an $\alpha+\beta$ bimodal microstructure usually have higher yield strength than alloys with a single $\beta$ phase microstructure, due to e.g., lengthscale strengthening. Therefore, it is of interest to ask whether an alloy with an $\alpha+\beta$ bimodal microstructure can be developed with mechanical twinning as the main deformation mechanism in the $\beta$ phase. In this case, the alloy should have a high yield strength, significant strain hardening and good ductility. This study presents an attempt to develop an alloy with an $\alpha+\beta$ bimodal microstructure and the $\beta$ phase that possesses the TWIP effect. In order to determine the TWIP composition of the $\beta$ phase, a $\beta$ Ti alloy (referred to as the $\beta$ alloy hereafter) was designed and tested, which shows the TWIP effect. Then another alloy (referred to as the $\alpha+\beta$ alloy hereafter) was designed and processed to obtain an $\alpha+\beta$ bimodal microstructure and the $\beta$ phase of similar composition to the $\beta$ alloy. Then the tensile behaviour of this alloy was studied.

\section{Experimental}

The nominal compositions of the $\beta$ alloy and $\alpha+\beta$ alloy were Ti- $0.5 \mathrm{Al}-6 \mathrm{Cr}-3 \mathrm{Mo}$ (wt. \%) and Ti- $0.6 \mathrm{Al}-0.4 \mathrm{~V}-4 \mathrm{Cr}-0.25 \mathrm{Fe}-1.5 \mathrm{Zr}-2 \mathrm{Zr}-0.07 \mathrm{O}$ (wt. \%). The alloys were prepared by vacuum arc melting using pure elements and TiO. The dimensions of the melted ingots were $23 \times 23 \times 56 \mathrm{~mm}^{3}$. Then the $\beta$ alloy was shape-rolled to a cross-section of $10 \times 10 \mathrm{~mm}^{2}$ in nine passes at $770{ }^{\circ} \mathrm{C}$ and annealed at $770{ }^{\circ} \mathrm{C}$ for $15 \mathrm{~min}$, and water quenched. In order to refine the grain size, the bar of the $\beta$ alloy was cold rolled with a $50 \%$ thickness reduction and flash annealed in the $\beta$ phase region at $960^{\circ} \mathrm{C}$ for $1 \mathrm{~min}$, then water quenched to retain a single $\beta$ phase microstructure. The $\alpha+\beta$ alloy was shape-rolled to a cross-section of $19 \times 19 \mathrm{~mm}^{2}$ at $1000{ }^{\circ} \mathrm{C}$ in three passes and shape-rolled to a cross section of $10 \times 10$ mm ${ }^{2}$ at 750 ${ }^{\circ} \mathrm{C}$ in six passes in the $\alpha+\beta$ phase region, then annealed at $700{ }^{\circ} \mathrm{C}$ for $12 \mathrm{~h}$ and water quenched to obtain an $\alpha+\beta$ bimodal microstructure, with the elemental partitioning between $\alpha$ and $\beta$ phases estimated by phase diagram calculations.

Tensile samples with gauge dimensions of $1.5 \times 1.5 \times 19 \mathrm{~mm}^{3}$ were machined along the rolling direction (RD) from the annealed alloys. Tensile tests were conducted on an Instron load frame with an extensometer at a nominal strain rate of $10^{-3} \mathrm{~s}^{-1}$.

Back scattered electron (BSE) micrographs and electron backscatter diffraction (EBSD) micrographs were obtained with a Zeiss Sigma 300 Field Emission Scanning Electron Microscope (FE-SEM). The composition of phases was examined using a Zeiss Auriga FE-SEM equipped with an energy dispersive spectrometer (EDS).

\section{Results and discussion}

(C) The Authors, published by EDP Sciences. This is an open access article distributed under the terms of the Creative Commons Attribution License 4.0 (http://creativecommons.org/licenses/by/4.0/). 
Fig. 1a shows the engineering stress-strain curves of both alloys. The two alloys have different tensile behaviour. The $\beta$ alloy possesses an excellent combination of high strength and high ductility. The engineering yield stress $\left(\sigma_{0.2}\right)$, tensile stress (TS) and total elongation (EL) of the $\beta$ alloy were $737 \mathrm{MPa}, 999 \mathrm{MPa}$ and $24 \%$, respectively. However, the $\sigma_{0.2}$, TS and EL of the $\alpha+\beta$ Alloy were $839 \mathrm{MPa}$, $904 \mathrm{MPa}$ and $14 \%$, respectively. The $\sigma_{0.2}$ of the $\alpha+\beta$ alloy is higher than that of the $\beta$ alloy, while the TS and EL are lower. The true stress-strain curves and work hardening rates of both alloys are shown in Fig. 1b. As can be seen, the $\beta$ alloy has very high ultimate tensile strength (1221 MPa) and large uniform elongation (0.2) in addition to a steady, high strain hardening rate. In contrast, the strain hardening rate of the $\alpha+\beta$ alloy decreases sharply to zero at true stain of 0.08 .
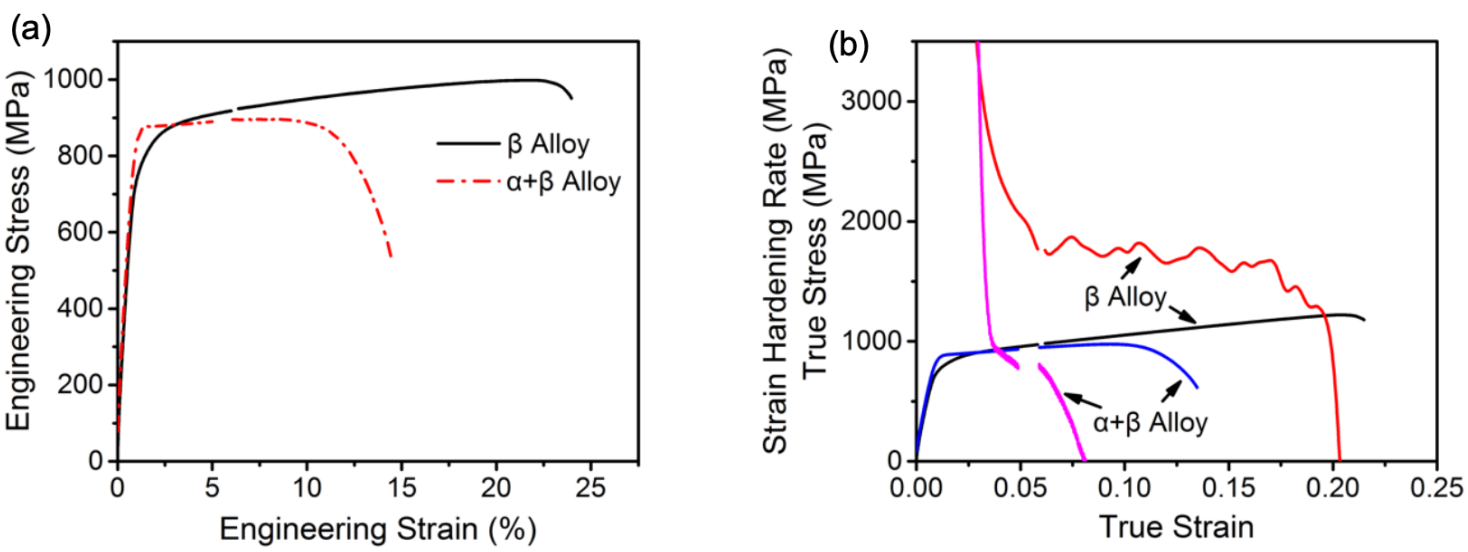

Fig. 1 (a) Engineering stress-strain curves and (b) true stress-strain curves and corresponding strain hardening rates of different alloys.

The elemental contents measured using SEM-EDS for both alloys are listed in Table 1 . The content of $\mathrm{Al}, \mathrm{Cr}$ and Mo in the $\beta$ alloy and in the $\beta$ phase in the $\alpha+\beta$ alloy were very similar. This indicates that the processing and heat treatments provided the results expected from thermodynamic modelling. Therefore, the stability of the $\beta$ phase in the two alloys should be similar.

Table 1 Elemental contents (wt. \%) measured using SEM-EDS for both alloys.

\begin{tabular}{|c|c|c|c|c|c|c|c|c|c|}
\hline & & $\mathrm{Al}$ & $\mathrm{Ti}$ & $\mathrm{V}$ & $\mathrm{Cr}$ & $\mathrm{Fe}$ & $\mathrm{Zr}$ & Mo & o \\
\hline \multirow[t]{2}{*}{$\beta$ Alloy } & Nominal & 0.5 & 90.5 & - & 6 & - & - & 3 & - \\
\hline & Measured & 0.49 & 89.93 & - & 6.46 & - & - & 3.11 & - \\
\hline \multirow[t]{4}{*}{$\alpha+\beta$ Alloy } & Nominal & 0.6 & 91.18 & 0.4 & 4 & 0.25 & 1.5 & 2 & 0.07 \\
\hline & Bulk & 0.61 & 90.54 & 0.53 & 3.96 & 0.30 & 1.74 & 2.33 & \\
\hline & $\alpha$ & 0.81 & 95.26 & 0.14 & 1.26 & 0.09 & 1.57 & 0.86 & \\
\hline & $\beta$ & 0.46 & 87.50 & 0.53 & 5.75 & 0.50 & 1.84 & 3.43 & \\
\hline
\end{tabular}

The microstructure before and after tensile tests for both alloys is shown in Fig. 2. As can be seen, the grain size of the $\beta$ Alloy, which is around $100 \mathrm{~mm}$, is much larger than that of the $\alpha+\beta$ Alloy, which is $1-4 \mathrm{~mm}$ for both $\alpha$ and $\beta$ phases. It is worth noting that the $\sigma_{0.2}$ of the $\beta$ alloy is just $\sim 100 \mathrm{MPa}$ lower than that of the $\alpha+\beta$ alloy even though the grain size of the $\beta$ Alloy is much larger than that of the $\alpha+\beta$ alloy. The deformed grains are full of bands for the $\beta$ alloy which intersect and divide the grain into smaller parts where needle-like features can be observed (indicated by the arrow in Fig. 2c). These bands also have a substructure consisting of smaller bands and needle-like structures. However, the deformed $\beta$ phase in the $\alpha+\beta$ alloy does not have the above characteristics. 

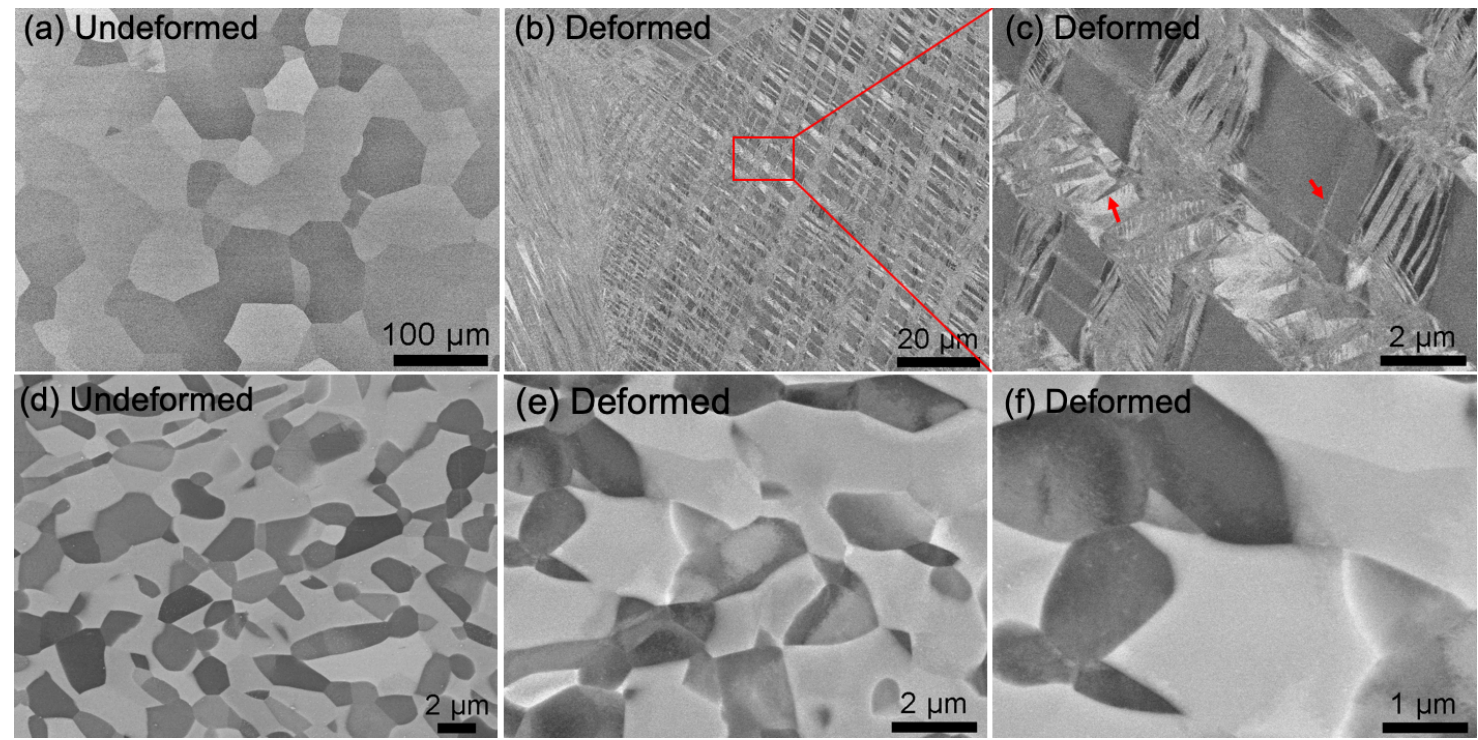

Fig. 2 Back scattered electron (BSE) micrographs of the $\beta$ alloy: (a), (b) and (c), and the $\alpha+\beta$ alloy: (d), (e) and (f). In (d), (e) and (f), the dark phase is a and bright phase is $\beta$.

From the phase distribution map of the $\beta$ alloy (Fig. 3a and b), it can be seen that the bands are still a bcc phase but with different crystal orientations from the $\beta$ matrix according to the inverse pole figure (IPF) (Fig. 3c-e). They were determined to be $\{332\}<113>$ twins by the IPFs (Fig. 3c-e) and pole figure (Fig. 3f). The needle-like feature is a hcp phase which is most likely the stress-induced $\alpha^{\prime}$ martensite, although further confirmation is needed [2,12]. Moreover, secondary twins and martensite may have formed in the primary twins as shown in Fig. 2. This has also been observed in prior work $[5,7]$. Therefore, it is believed that both TWIP and TRIP have occurred during tensile tests of the $\beta$ alloy, which accounts for the steady high strain hardening rate during the tensile tests. On the other hand, no mechanical twins and martensite were found in the $\beta$ phase in the deformed the $\alpha+\beta$ alloy, which indicates that the deformation mechanism was dislocation glide. This is in concordance with the lack of strain hardening observed in the tensile test results for this alloy. 

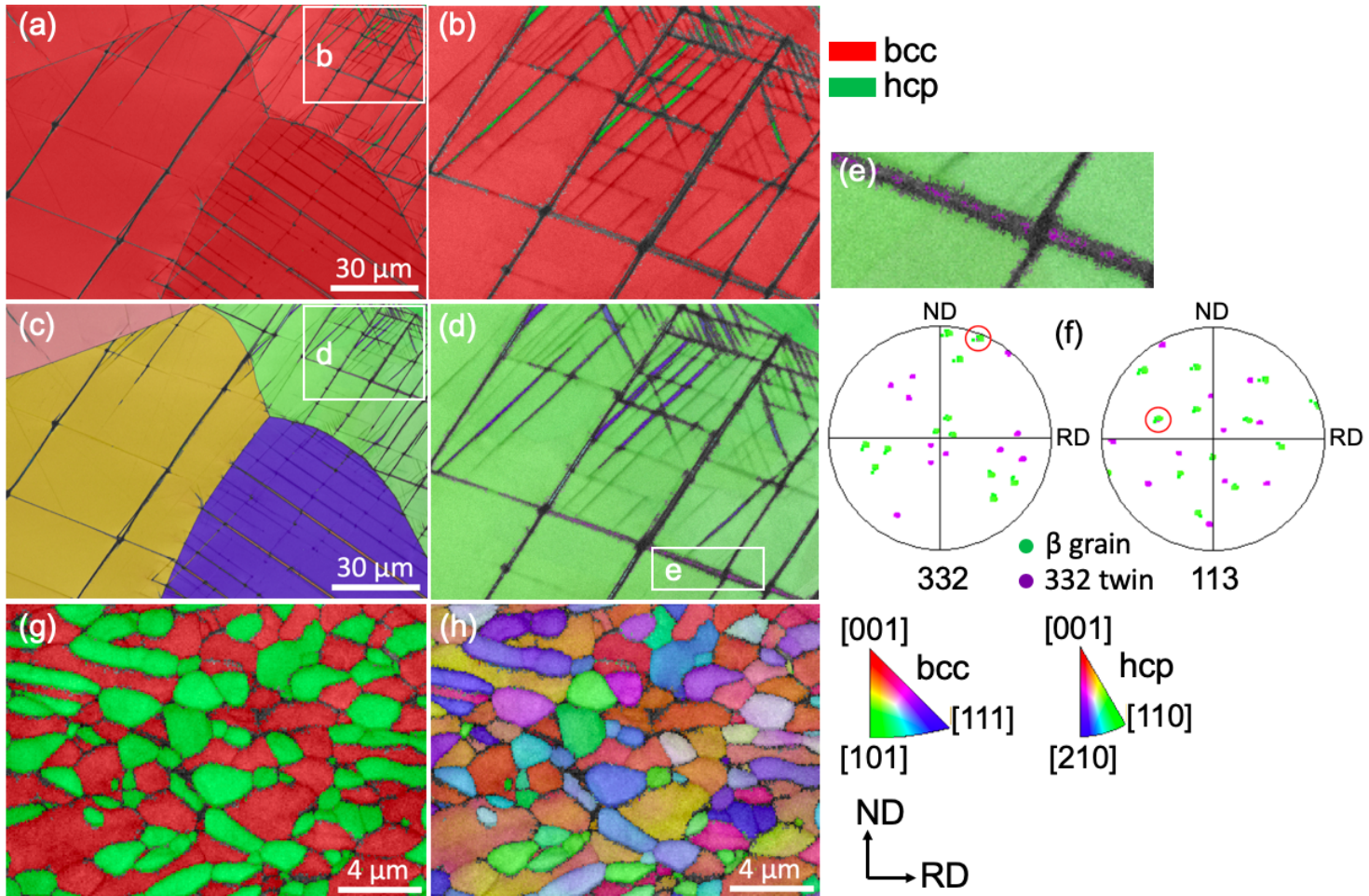

[001]

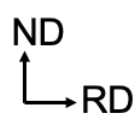

Fig. 3 EBSD maps of the specimen gauge after tensile tests: (a) and (b) the phase distribution map (the red colour represents bec $\beta$ and green colour represents hep $\alpha$ and stress-induced martensite), (c)-(e) inverse pole figure (IPF) map of the $\beta$ alloy, (f) the pole figure of (e) showing $\{332\}<113>$ twins in the $\beta$ alloy; (g) the phase distribution map and (h) IPF map of the $\alpha+\beta$ alloy.

Mechanical twins and stress-induced martensite indicate that the $\beta$ phase in the $\beta$ alloy is metastable. As can be seen from Table 1 , the $\beta$ phase in the $\alpha+\beta$ alloy has similar contents of Al, Cr and Mo as the $\beta$ Alloy. Nevertheless, it seems much more stable than the $\beta$ phase in the $\beta$ alloy. Possible reasons for this may be (1) the small grain size of the $\alpha+\beta$ alloy, (2) the extra elements in the $\alpha+\beta$ alloy, and (3) the presence of $\alpha$ phase. Prior work $[13,14]$ has shown that the grain size has a significant effect on the twinning behaviour and stress-induced martensite transformation. However, even when we refined the $\beta$ grains to $5 \mu \mathrm{m}$ in a $\beta$ alloy having a similar composition with that studied here, the deformation twinning of the $\beta$ was still observed. Hence, grain size is not the cause of the transition from twinning to slip. The extra elements in the $\alpha+\beta$ alloy included $\mathrm{V}$ and Fe as $\beta$ stabilisers. Although their content in the $\beta$ are low, the stability of $\beta$ may still be increased. Zr is a neutral element. Its effect on twinning is not clear. However, the $\mathrm{B}_{0}$ and $\mathrm{Md}$ values of $\mathrm{Zr}$ are relatively large [8], which may mean that it has important effects on $\beta$ stability. Therefore, further consideration of alloying is required to design a TWIP $\alpha+\beta$ alloy. Moreover, the presence of $\alpha$ could lead to a different partitioning of stress and strain, and to differences in the dislocation behaviours that can co-deform both phases. This area needs further study.

\section{Summary}

A $\beta$ Ti alloy was designed that exhibits an excellent combination of high strength and high ductility. It also shows a high steady strain hardening rate due to the TWIP and TRIP effects. Moreover, an attempt has been carried out to develop an $\alpha+\beta$ alloy with a bimodal microstructure, expecting that the $\beta$ phase would twin during deformation. The content of the major $\alpha$ and $\beta$ stabilising elements, i.e. $\mathrm{Al}, \mathrm{Cr}$ and Mo, in the $\beta$ phase of the $\alpha+\beta$ alloy was tuned to be similar to the $\beta$ alloy. However, the $\beta$ phase of the $\alpha+\beta$ alloy was too stable to twin during deformation. The possible reasons are suggested to be that (1) the extra V, Fe and Zr over stabilize the $\beta$ phase and (2) the stress and strain distribution may be different in the $\alpha+\beta$ alloy due to the existence of the $\alpha$ phase

\section{Acknowledgements}

This work was financially supported by the UK Engineering and Physical Sciences Research Council (EPSRC) under the DARE Programme. The authors would like to thank all members of the Dye Group at Imperial College London for help.

\section{References}

[1] G. Lütjering, J.C. Williams, Titanium, Springer Berlin Heidelberg, Berlin, Heidelberg, 2007. 
[2] M. Marteleur, F. Sun, T. Gloriant, P. Vermaut, P.J. Jacques, F. Prima, Scr. Mater. 66 (2012) 749-752.

[3] B.C. De Cooman, K. Chin, J. Kim, High Mn TWIP steels for automotive applications, in: New Trends Dev. Automot. Syst. Eng., IntechOpen, 2011.

[4] D. Kuroda, M. Niinomi, M. Morinaga, Y. Kato, T. Yashiro, Mater. Sci. Eng. A. 243 (1998) 244-249.

[5] S. Sadeghpour, S.M. Abbasi, M. Morakabati, A. Kisko, L.P. Karjalainen, D.A. Porter, Scr. Mater. 145 (2018) 104-108.

[6] S. Sadeghpour, S.M. Abbasi, M. Morakabati, J. Alloys Compd. 650 (2015) 22-29.

[7] J. Zhang, F. Sun, Z. Chen, Y. Yang, B. Shen, J. Li, F. Prima, Mater. Res. Lett. 7 (2019) 251-257.

[8] M. Abdel-Hady, K. Hinoshita, M. Morinaga, Scr. Mater. 55 (2006) 477-480.

[9] C. Brozek, F. Sun, P. Vermaut, Y. Millet, A. Lenain, D. Embury, P.J. Jacques, F. Prima, Scr. Mater. 114 (2016) 60-64.

[10] F. Sun, J.Y. Zhang, M. Marteleur, C. Brozek, E.F. Rauch, M. Veron, P. Vermaut, P.J. Jacques, F. Prima, Scr. Mater. 94 (2015) 17-20.

[11] J.Y. Zhang, J.S. Li, Z. Chen, Q.K. Meng, F. Sun, B.L. Shen, J. Alloys Compd. 699 (2017) 775-782.

[12] F. Sun, J.Y. Zhang, M. Marteleur, T. Gloriant, P. Vermaut, D. Laillé, P. Castany, C. Curfs, P.J. Jacques, F. Prima, Acta Mater. 61 (2013) $6406-6417$.

[13] Q. Yu, Z.W. Shan, J. Li, X. Huang, L. Xiao, J. Sun, E. Ma, Nature. 463 (2010) 335-338.

[14] M.H. Cai, C.Y. Lee, Y.K. Lee, Scr. Mater. 66 (2012) 606-609. 